\begin{tabular}{ccc}
\hline & International Journal of Engineering \& Technology, $7(2.29)(2018) 352-355$ \\
SPC & International Journal of Engineering \& Technology \\
Website www.sciencepubco.com/index.php/IJET & Research paper \\
\hline
\end{tabular}

\title{
Identification of The Concept Selection Method for Product Design and Development in The Manufacturing Industry
}

\author{
Shiau Wei Chan ${ }^{1 *}$, Izzuddin Zaman², Md Fauzi Ahmad ${ }^{3}$, Check Yee Liew ${ }^{4}$
}

\begin{abstract}
${ }^{1}$ Faculty Of Technology Management And Business, Universiti Tun Hussein Onn Malaysia, 86400 Batu Pahat, Johor, Malaysia ${ }^{2}$ Faculty Of Technology Management And Business, Universiti Tun Hussein Onn Malaysia, 86400 Batu Pahat, Johor, Malaysia ${ }^{3}$ Faculty Of Technology Management And Business, Universiti Tun Hussein Onn Malaysia, 86400 Batu Pahat, Johor, Malaysia ${ }^{4}$ Faculty Of Mechanical And Manufacturing Engineering,, Universiti Tun Hussein Onn Malaysia, 86400 Batu Pahat, Johor, Malaysia *Corresponding Author E-Mail: Swchan@Uthm.Edu.My
\end{abstract}

\begin{abstract}
Concept selection is the most critical aspect of the entire product development process. However, many industries are not aware of this, or they might not possess essential knowledge about concept selection. Thus, this study aims to identify the concept selection method used by a series of particular areas within the manufacturing industry. In this study, the researcher conducted interviews with six managers from various production areas in the manufacturing industry. Then, the obtained data were analyzed qualitatively. The concept selection methods used for product design and development in the manufacturing industry were found to be based on various factors, including orders received, building and evaluating prototypes, discussion among executives, market demand, trial and error and the market's standard deviation. This study serves as a guideline to help managers to evaluate concepts in a more practical way.
\end{abstract}

Keywords:Production;Conceptselectionmethod;Productdesignanddevelopment

\section{Introduction}

A huge portion of product and lifecycle cost is invested during the development of concepts and the concept selection stage 1 . Therefore, choosing the most appropriate product concept is the most crucial action in the product development environment. The concept selection method is a typical example of multi-criteria decision making (MCDM), which selects the best concept among the alternatives during early product design and development phases $\stackrel{2}{2}$. The concept evaluation and concept selection stages are necessary for a project to reach high value, as the chosen concepts will decide the movement of the detailed design phase $\stackrel{3}{\text {. Organizations }}$ regard the multi-criteria decision making technique for concept selection as an ideal solution ${ }^{2}$. There has been increased research interest in proper concurrent consideration of the design concept and material at the initial stage of product development $\stackrel{4}{\text {. }}$.

However, the uncertainties and inconsistencies of marketing requirements have meant that concept selection has become very challenging $\underline{5}$. Over the years, people have failed to pay sufficient attention to concept selection as an area of design research. Moreover, the industry has very limited knowledge about the methods used in design research. Besides, a majority of industries have been found to be lacking in adequate and appropriate methods for concept selection because they fail to conduct formal methods of concept selection ${ }^{6}$. The product may need to be redesigned or remanufactured because of irrelevant decision-making during design concept selection at the conceptual design stage ${ }^{4}$. An impoverished product concept may lead to suspension in product understanding and tremendous redesign cost, and might also jeop- ardize the chance of profitable commercialization ${ }^{7}$. Additionally, the impoverished design concept is unlikely to be reimbursed in the followed design stages $\underline{8}$. Other than the waste of costs for extra tooling investments and engineering hours, the failure may also lead to frustration among the management and co-workers 9 . Thus, the level of success of product design achieved is strongly dependent on the initial concept at the early stage of the product development process. Therefore, this research sets out to identify whether the manufacturing industry practices the use of concept selection methods in product development. It is essential to choose the most suitable design concepts.

\section{Literature Review}

Ulrich \& Eppinger 10 define a product as something that an enterprise sells to its customers. Further, they define "product development" as "the set of activities beginning with the perception of a market opportunity and ending in the production, sale, and delivery of a product" (p.2). Another definition states that product development means a process that has multiple stages, and sometimes includes risks, unpredictable factors, and a very high development cost $\underline{11}$. Kahn $\underline{12}$ stated that product development is the comprehensive process of organization, concept generation, concept selection, strategy, creation and evaluation of the product and marketing plan and commercialization of a new product.

From the perspective of the investors in a for-profit enterprise, successful product development results in products that can be produced and sold profitably. Therefore, five specific dimensions, all of which ultimately relate to profit, are commonly used to access the performance of a product development effort. These are 
10: (1) Product Quality: How good is the product resulting from the development effort? Does it satisfy customer needs? Is it robust and reliable? Product quality is ultimately reflected in market share and the price that customers are willing to pay; (2) Product Cost: What is the manufacturing cost of the product? This cost includes spending on capital equipment and tooling as well as the incremental cost of producing each unit of the product. Product cost determines how much profit accrues to the firm for a particular sales volume and a particular sales price; (3) Development Time: How quickly did the team complete the product development effort? Development time determines how responsive the firm can be to competitive forces and to technological developments, as well as how quickly the firm receives the economic returns from the team's efforts; (4) Development Cost: How much did the firm have to spend to develop the product? Development cost is usually a significant fraction of the investment required to achieve the profits; (5) Development Capability: Are the team and the firm better able to develop future products as a result of their experience with a product development project? Development capability is an asset for the firm, enabling it to develop products more effectively and economically in the future.

Concept selection is the climax in the product design and development process. It is crucial that the starting concepts are chosen well, as they will determine the direction of the design embodiment stage ${ }^{3}$. Concept selection focuses mainly on the early stage of the product development project, during which the product developing organization has to identify what to pursue in the subsequent stages of detailed product development ${ }^{9}$. Designers have to judge an increasing quantity of design options in order to produce more innovative product in an increasingly competitive market field. This is essential in the initial conceptual phase of the design process, when a large number of design alternatives are available.

\section{Methodology}

\subsection{Research Design}

This is a qualitative study, which sets out to understand better and acquire insight into the phenomenon of interest and construct explanations or theory $\underline{13}$. Qualitative research helps researchers to develop a clearer view of what people say and do, and to understand better the social and cultural contexts within which people

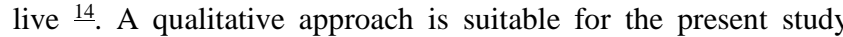
because it helps to gain more information about the concept selection method used in the manufacturing industry. Interview data were utilized as the qualitative data. The researcher transcribed the audio-recordings of the interviews and then analyzed the transcripts, using tables for the data display.

\subsection{Respondents}

Sampling is crucial in this type of study because it is extremely costly and time-consuming to study a large population. Purposive sampling is a non-probability sampling strategy that integrates

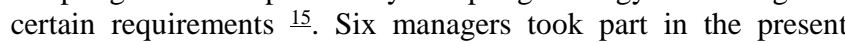
study. They were Research and Development Managers who were chosen purposively from six manufacturing industries because they were involved in product concept selection. The products produced by the six manufacturing industries are as follows: Company A - plastic chips for manufacturing; Company B - furniture; Company $\mathrm{C}$ - mattresses; Company $\mathrm{D}$ - furniture; Company $\mathrm{E}$ - processed food; Company $\mathrm{F}$ - air conditioning gas.

\subsection{Instrumentation}

This study was carried out through conducting interviews, using interview questions as instruments. Interviewing is an important technique for qualitative research because it enables the collection of rich data from people in various roles and situations ${ }^{14}$. The researcher created a set of interview questions with seven items for the interview. Five items were constructed based on the five specific dimensions proposed by $\underline{10}$. Then, inter-rater agreement was sought to confirm the reliability of this instrument $\underline{16}$. The interview questions were checked by two experts in the product development field. Both raters were asked to judge the appropriateness of the items. The researcher made corrections based on the opinions and recommendations from the raters. During the interviews, the whole process was audio-taped using a voice recorder. The researcher transcribed the interview protocols and tabulated and categorized the data using the Nvivo 10 software.

\section{Findings}

\subsection{Concept Selection Method Used}

Different industries practice different methods of concept selection. Even if they are producing similar types of products, the concept selection methods can still be different. A summary of the concept selection methods used by the different industries in the present study is shown in Table 1 .

Table 1. Concept selection methods used by different industries

\begin{tabular}{|c|c|}
\hline Company & Concept Selection Method used \\
\hline A & Based on orders received \\
\hline B & Build prototype and evaluate \\
\hline C & Discuss among executives \\
\hline D & Based on market demand \\
\hline E & Trial and error \\
\hline F & Based on market's standard deviation \\
\hline
\end{tabular}

Company A manufactures their product based on the orders they received from their supplier. Therefore, this company does not need to undertake much consideration about selecting a product concept. However, they still need to consider product quality, product cost, and development capability. This is because different concepts may result in differences in product quality, product cost and development capability. Their ways of producing such products neglect to consider product quality, product cost and development capability. An important specific dimension to utilize a product concept to bring high profit in return is to consider its product cost.

Company B builds several prototypes based on the alternative product concepts that they already have in planning. They then evaluate those prototypes with regard to the aspects of product quality, product design, product shape and size, material used, and product cost. The company then selects the most suitable product based on the prototypes built. By using this method, this company can consider the quality and cost of products as well as development capability.

Company $\mathrm{C}$ conducts a meeting for a few executives to discuss what the product should be and how it should be developed. They may have a few concepts in mind, and then they evaluate each concept based on the product quality, product cost and development capability. During the discussion, every executive gives different opinions and suggestions, after which they will finally decide on an optimum concept upon which everyone agrees. However, this method does not cover the discussion on development time and development cost.

Company D develops a few product concepts for idea screening. They show the choices of ideas to their clients, who then make their orders for products they are interested in. The orders received will then undergo the next step, which is the production of the products. The productions are based on the orders received: thus, the company does not need to store excess products or consider what to do about unsold products. The remaining concepts that 
were not chosen will be kept in storage but no longer published as product options. This method mainly focuses on the product cost, development time, development cost and development capability Company D does not focus on product quality because their product focus is on the medium to low range, which frees them from the restriction of ensuring that their products are of good quality.

Company E tries out new product concepts by using a trial and error method. They design, develop and manufacture a new product in considerable numbers, and then wait and assess the response from the market demand. If the product sells at a good rate, they will continue to produce and sell it. But if it does not sell well, they will stop producing the product and head for another one. The cycle starts and ends like this for every single new product concept. This method enables them to have short development time: the period from product design and development to product launch does not have to be long. However, this method does not focus on product quality, product cost, development cost or development capability.

Company F designs and develops their product concept according to the market's standard deviation. They design their product based on the most commonly required amounts for different fields. Their product is unique, so there is not much variation between types: the only variation is in the number of units produced. This method is concerned with development time because not much planning is needed, and it is also concerned with development cost. However, this method does not focus on product quality, product cost or development capability.

\subsection{Five Specific Dimensions within the Concept Selection Method}

Table 2 illustrates the concerns of five specific dimensions of the concept selection method used by six different companies.

Table 2. Five Specific Dimensions on Concept SelectionMethod

\begin{tabular}{|l|l|l|l|l|l|l|}
\hline \multirow{2}{*}{ Dimension } & \multicolumn{7}{|c|}{ Company } \\
\cline { 2 - 8 } & A & B & C & D & E & F \\
\hline Product Quality & & $\sqrt{ }$ & $\sqrt{ }$ & & & \\
\hline Product Cost & & $\sqrt{ }$ & $\sqrt{ }$ & $\sqrt{ }$ & & \\
\hline Development Time & $\sqrt{ }$ & & & & $\sqrt{ }$ & $\sqrt{ }$ \\
\hline Development Cost & $\sqrt{ }$ & $\sqrt{ }$ & & & $\sqrt{ }$ & $\sqrt{ }$ \\
\hline Development Capability & & $\sqrt{ }$ & $\sqrt{ }$ & $\sqrt{ }$ & $\sqrt{ }$ & \\
\hline
\end{tabular}

In this study, the major concern about product quality is to satisfy customer needs and to design a robust and reliable product. The researcher found that two of the six companies focus on product quality in their product concept selection methods. With regard to product cost, three of the six companies focus on product cost in their product concept selection method. Many companies are trying to achieve lower product costs, because this is the main purpose of doing business. The revenue in return is the final goal towards which every business is heading. However, some of the companies in this study do not focus on cutting product costs to make profit: instead, they focus on production in large quantities to ensure that they can make a profit. For development time, three of the six companies focus on development time in their product concept selection method. Some companies ensure their market compatibility by reducing the development time to speed up their financial return from the team's efforts. It is also important not to waste excessive resources such as time and money on product design, because this will greatly reduce the efficiency and return of profit.

Pertaining to development cost, four companies focus on development cost in their product concept selection method. These companies considered investing in development costs, but with appropriate judgment. Others had their development costs paid by other sides of their businesses: therefore, their development costs were relatively low. With reference to development capability, the researcher found that four of the six companies focused on development capability in their product concept selection methods. Most of the companies agreed that it is important to have development capability, as it is an important asset of the company and can ensure the development of new products and future economic benefits.

\section{Conclusion}

The objectives of this study were achieved through interviews with six respondents who are involved in product concept design and development in the manufacturing industry. The objective of the study is to identify the method used for concept selection in the manufacturing industry. Through the interviews, the product concept selection methods used were based on orders received, building and evaluating prototypes, discussion among executives, market demand, trial and error, and market standard deviation.

Concept selection is a very important stage in the product development process, because it greatly affects upstream and downstream activities in a new product development environment. Choosing the most suitable and strategic concept is very important in product development. Inconsistent and inappropriate product requirements mean that it has become very challenging to make the final decision on concept selection5. Organizations that fail to handle their product development activities precisely are not only running their businesses from a position of detriment, but also endangering their future 17. To minimize the consequences and unpredictable changes, organizations have to judge their new product initiatives precisely and make strategic decisions. Organizations can successfully enhance the accuracy of their new product evaluation decisions, although the result of a new product evaluation decision can be affected by environmental uncertainties that are beyond an organization's ability to control 18 .

Although the research has achieved its objectives, there were some unavoidable limitations. There are two major limitations in the study, which are number of respondents and cooperation from interviewees. There were only six managers involved in the present study, so this sample cannot represent the overall population. Furthermore, some of the interviewees were unwilling to provide relevant information such as costing and development details. In addition, some of the interviewees were busy with their daily tasks and were unable to conduct interviews with the researcher. For future studies, the dependent variable should not only focus on the manufacturing industry, but should also study other fields of industry. Moreover, this study only focused on the manufacturing industry within Batu Pahat, Malaysia: future research should extend its scope to other states or other countries.

\section{Acknowledgement}

This work was supported by universiti tun hussein onn malaysia under grant no. U431.

\section{References}

[1] Z. Ayag, and R. G. Ozdem, An analytic network process-based approach to concept evaluation in a new product development environment. Journal of Engineering Design, 18, 209-226 (2007).

[2] D. R. Cooper, and P. S. Schindler, Business Research Methods (3rd ed.). New York: McGraw-Hill (2011).

[3] J. A. Fitzsimmons, P. Kouvelis, and D. N. Mallick, Design strategy and its interface with manufacturing and marketing: A conceptual framework. Journal of Operations Management, 10, 398 - 415 (1991).

[4] R. Y. K. Fung, Y. Chen, and J. Tang, A quality-engineering-based approach for conceptual product design. The International Journal of Advanced Manufacturing Technology, 32(11), 1064 - 1073 (2007). 
[5] P. Ghauri, \& K. Gronhaug, Research methods in business studies (4th ed.). London: Pearson Education Ltd (2010).

[6] A. Hambali, S. M. Sapuan, A. S. Rahim, N. Ismail, N., and Y. Nukman, Concurrent decisions on design concept and material using Analytical Hierarchy Process at the conceptual design stage. Concurrent Engineering, 19(2), 111-121 (2011).

[7] K. B. Kahn, PDMA Handbook of new product development (2nd ed.). Hoboken: John Wiley \& Sons, Inc (2007).

[8] I. Kihlander, Decision making in concept phases: Towards improving development processes. Licentiate Thesis, Royal Institute of Technology (2009).

[9] A. M. King, and S. Sivaloganathan, Development of a methodology for concept selection in flexible design strategies. Journal of Engineering Design, 10(4), 329-349 (1999).

[10] W. F. Lu, J. Sun, H. T. Loh, and C. W. Chua, Concept selection for market potential using fuzzy selection approach. 2008 IEEE International Conference on Industrial Engineering and Engineering Management, 1699-1703 (2008).

[11] M. D. Myer, Qualitative research in business \& management. New York: SAGE Publications Ltd (2009).

[12] J. L. Nevins, and D. E. Whitney, Concurrent design of products and processes: a strategy for the next generation in manufacturing. McGraw-Hill, New York (1989).

[13] M. Ozer, Factors which influence decision making in new product evaluation. European Journal of Operational Research, 163(3), 784-801 (2005).

[14] M. Salonen, and M. Perttula, Utilization of concept selection methods: A survey of Finnish Industry. Proceedings of 17th International Conference on design theory and methodology, 24-28 September, 2005. USA: California (2005).

[15] R. E. Slavin, Educational research in an age of accountability. United States of America: Pearson Education, Inc (2007).

[16] K. T. Ulrich, and S. D. Eppinger, Product Design and Development (5th ed.). New York : McGraw-Hill (2012).

[17] S. Vinodh, G. Mulanjur, and A. Thiagarajan, Sustainable concept selection using modified fuzzy TOPSIS: a case study. International Journal of Sustainable Engineering, 6(2), 109-116 (2013).

[18] J. Wang, Improved enginnering design concept selection using fuzzy set. International Journal of Computer Integrated Manufacturing, 15(1), $18-27$ (2002). 